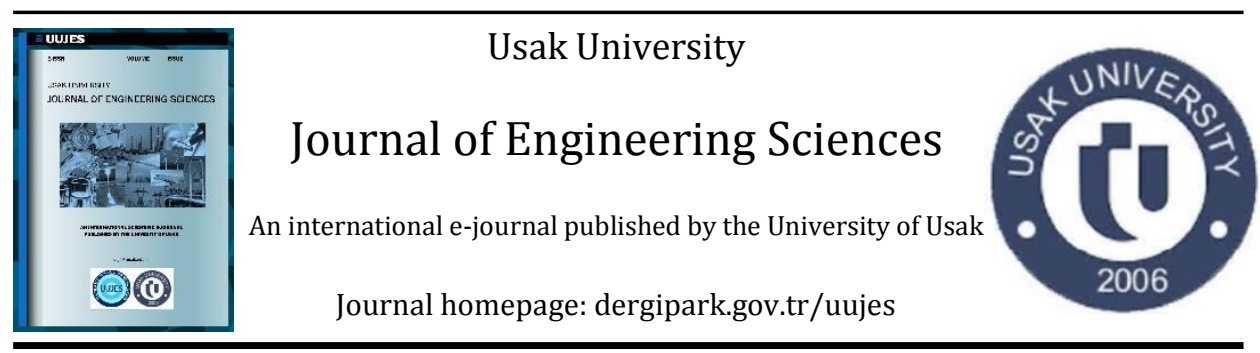

Research article

\title{
SYNTHESIS OF Ag-DOPED ZnO NANOMATERIALS FOR DYE SENSITIZED SOLAR CELLS AND INVESTIGATION OF THE OPTIMUM Ag DOPING RATE
}

\author{
Mesut Ekmekci ${ }^{*}$, Cagatay Ela ${ }^{2}$, Sule Erten-Ela², Cagdas Yavuz ${ }^{2}$ \\ ${ }^{I}$ Vocational High School of Technical Sciences, Uşak University, Uşak, Turkey \\ ${ }^{2}$ Graduate School of Solar Energy, Ege University, İmir, Turkey
}

Received: 1 November 2021 Revised: 26 December 2021 Accepted: 13 December 2021 Online available: 28 December 2021 Handling Editor: Ayşen Melda Çolak

\begin{abstract}
Silver (Ag) doped ZnO (SZO) nanomaterials were synthesized by hydrothermal method and characterized. $\mathrm{ZnO}$ nanostructures were doped with $0.0 \%, 0.5 \%, 1 \%, 1.5 \mathrm{~mol} \%$ Ag. These obtained SZO nanomaterials were analyzed using X-ray diffraction measurement (XRD), Scanning Electron Microscopy (SEM), and Energy Dissipative X-ray (EDX) spectroscopy. The structural analysis confirmed the formation of synthesized SZO samples having a hexagonal ZnO wurtzite phase. The morphology of SZO samples changed partially and the $\mathrm{ZnO}$ nanorod length increased somewhat as the Ag doping ratio increased. Despite this increase, it was seen that the average crystal sizes first increased and then decreased. The crystallite sizes calculated from XRD data for 0.0, 0.5, 1.0 and 1.5mol\% SZO were obtained as 41, 42, 38 and $37 \mathrm{~nm}$, respectively. Ag doping concentration has increased the absorbance of SZO nanomaterials increased and the transmission decreased was observed. The band gap of the $0.0 \%, 0.5 \%, 1.0 \%$ and $1.5 \mathrm{~mol} \%$ SZO nanomaterials were measured $3.19,3.18,3.16$ and $3.19 \mathrm{eV}$, respectively. Then dye sensitized solar cells (DSSCs) were fabricated using these SZO nanomaterials, cis-Bis(isothiocyanato) $\left(2,2^{\prime}\right.$ bipyridyl-4,4'-dicarboxylato) (4,4'-di-nonyl-2'-bipyridyl) ruthenium (II) dye (Z907), (Ditetrabutylammonium cis-bis(isothiocyanato) bis (2,20-bipyridyl-4,40 dicarboxylato) ruthenium (II) dye (N719) and examined their photovoltaic performances. The calculated efficiencies of DSSCs fabricated using Z907 dye for $0.0 \%, 0.5 \%, 1.0 \%$ and $1.5 \mathrm{~mol} \%$ SZO were $0.005,0.51,0.46$ and $0.22 \%$, respectively. Then the calculated efficiencies of DSSCs fabricated using N719 dye for $0.0 \%, 0.5 \%, 1.0 \%$ and $1.5 \mathrm{~mol} \%$ SZO were $0.06,0.17,0.07$ and $0.06 \%$, respectively. In both works, DSSCs with ZnO film doped with $0.5 \mathrm{~mol} \%$ SZO showed the best photovoltaic performance. Consequently, these results indicated that the synthesized SZO nanomaterial for DSSCs of the optimum ratio of Ag doping is $0.5 \mathrm{~mol} \%$ clearly.
\end{abstract}

Keywords: Silver (Ag) doped ZnO, ZnO films, dye sensitized solar cell, DSSC, photoanot.

(C)2021 Usak University all rights reserved.

\footnotetext{
*Corresponding author: Mesut Ekmekçi

E-mail: mesut.ekmekci@usak.edu.tr (ORCID 0000-0001-7170-0010)

DOI: $10.47137 /$ uujes.1016758
}

(C)2021 Usak University all rights reserved. 


\section{Introduction}

Renewable energy sources are sustainable and clean alternative energy sources. Among the renewable energy sources, solar energy is gaining importance day by day. Solar energy is an inexhaustible source of energy without CO2 emissions. PV solar cells have the advantages of low maintenance and environmental friendliness, and there are already many applications. DSSCs, which are the new generation solar cells, have attracted great interest in recent years due to their low cost and other advantages. DSSCs have attracted great interest as an alternative to traditional silicon solar cells, especially after the pioneering work of O'Regan and Gr"atzel [1]. Today they have a power conversion efficiency (PCE) of $14.3 \%$. DSSCs consist of a semiconductor photoanode (working electrode) coated with dye on a conductive substrate, a counter electrode and electrolyte solution containing a redox couple $\left(\mathrm{I}^{-} / \boldsymbol{I}_{3}^{-}\right)$.

Nanomaterials; they are polymers, metals, ceramics or nanocomposite materials ranging in size from 1 to 100 nanometers. Today, medical, imaging, pharmaceutical, automotive, textile, electronics, optics, aerospace industry and renewable energy have many applications in the field [2]. The reason for the increase in research on the synthesis and characterization of nanosized particles is the observation of quantum behaviors in the presence of known classical behaviors and the observation of unusual changes in the physical and chemical properties of the material if the size of the material falls into the nanometer range. For example, one-dimensional carbon atoms found on the nanometer scale exhibit a property that can provide even better transmission than gold and silver chains [3], even though the diamond crystal of carbon atoms is a good insulator. At the same time, a foreign atom connected to the outside system can exhibit very different and extraordinary behaviors according to its position in the structure and can change the magnetic and electrical properties of the nano-sized material [4]. The properties expected of a nanoparticle in good quality; the material may have a suitable particle size, large surface area and large pore volume. At the same time, the chemical, thermal, hydrothermal and mechanical strength of the material is expected to be high. New nanomaterials which synthesized are used as electron transfer mechanism in different devices, as photoanode and counter electrode in photoelectrochemical, DSSC and other solar cell technologies [5- 8].

Zinc oxide (ZnO) is a II-VI group and n-type semiconductor material [9]. Furthermore $\mathrm{ZnO}$ thin films have wide band gap (3.35-3.37 eV) [10], high exciton binding energy ( $\sim 60$ $\mathrm{meV}$ ) [11], piezoelectric properties, high transparency, and ferromagnetism properties at room temperature. For this reason, these films are used in sensors, piezoelectric materials, organic light-emitting [12], DSSCs, photocatalytic processes, transparent conductive oxide (TCO) [13]. ZnO thin films are produced via spray pyrolysis, pulsed laser deposition (PLD) [14], sputtering [15], molecular beam epitaxy (MBE) [16], electron beam evaporation [17], chemical vapor deposition [18], microwave-assisted synthesis[19] and sol-gel methods [20]. Un-doped ZnO thin films, despite their advantages, are not preferred due to their instability and low conductivity at high temperatures. For this reason $\mathrm{ZnO}$ is doped with some elements such as aluminium [21], magnesium [22], gallium [23,24], silver [25-28], titanium [29], copper [30,31], and tellurium[32]. With this doping, the morphological properties and performance of $\mathrm{ZnO}$ varies and become suitable for a variety of uses. 
The doping of $\mathrm{ZnO}$ nanomaterials with metal ions is a process that not only improves the electrical, semiconductor, optical and mechanical properties of the material but also causes a significant change in the particle size of the material. This process causes significant changes in the crystal structure and surface / volume ratio of the nanomaterial [33-36] SZO nanomaterials are noble metal ion doped $\mathrm{ZnO}$ nanomaterials. Silver, a bright white metal, has a density of 10.5 , a melting point of $960^{\circ} \mathrm{C}$, and a boiling point of $2212^{\circ} \mathrm{C}$. Along with copper and gold, their elements are in the IB cluster of the classification chart. Silver, which is extremely soft, conveys heat and electricity very well; for this reason it is used in electricity. It is attached to centrally-faced cubic systems: Hardness is low. Silver tends to form covalent compounds. Along with the basic oxidation level +1 , there are also +2 and +3 valences which approach the silver transition elements. In recent years, SZO nanostructures such as nanofibers, nanoneedles, nanowires, nanorods [37,38], nanospheres and 3D hollow micro- / nanospheres have been produced by Zinc Oxide silver doping and reported in the literature [9,39-42].

The determination of optimum doping ratio is significant to prevent excessive cost and material use in material synthesized processing. The main goal of the current study was to synthesize the SZO nanomaterials using different doping rates for DSSCs and investigate the optimum ratio of Ag doping. In the present work, SZO nanomaterials were successfully synthesized using the hydrothermal production method with doping concentrations of $0.0,0.5,1.0$, and $1.5 \% \mathrm{Ag}$ and characterized by XRD, SEM and EDX analysis. Two types of SZO based DSSC were fabricated using Z907 and N719 dyes. SZO films act as photoanodes in DSSCs. Structure and optical properties of SZO samples have also been examined. The photovoltaic performance of SZO based DSSCs were analyzed and investigated the optimum Ag doping rate.

\section{Materials and Method}

XRD Crystal structures and crystallite sizes (D) of SZO samples were determined using Cu K $\alpha$ radiation (1.540 A) Rigaku Equipment. During this inspection, current and voltage were keep at $40 \mathrm{~mA}$ and $40 \mathrm{kV}$, respectively. The morphologies of the prepared SZO samples were investigated by SEM studies. Morphological characterizations of the samples were performed using the Philips XL 30S FEG, SEM equipped with SEM-EDX. The current voltage of DSSC fabricated using these samples was characterized by (J-V) measurement. These examinations and measurements were executed under conditions of light intensity of $100 \mathrm{~mW} / \mathrm{cm}^{2}$ and AM 1.5. Radiant intensity at various densities were provided by A $450 \mathrm{~W}$ Xenon light source (Oriel) device. The Keithley 2400 Welding Meter and LabView data acquisition software was used for J-V data acquisition.

\subsection{Synthesis of SZOs}

SZO nanostructures are produced in a typical synthesis using zinc nitrate hexahydrate $\left(\mathrm{Zn}\left(\mathrm{NO}_{3}\right) 2.6 \mathrm{H}_{2} \mathrm{O}\right)$, silver nitrate $\left(\mathrm{AgNO}_{3}\right)$ and $\mathrm{NaOH}$ in a microwave oven using simple hydrothermal production method. These chemicals used were purchased from SigmaAldrich and used as purchased without any modifications. $3.15 \mathrm{mmol}$ of $\mathrm{Zn}\left(\mathrm{NO}_{3}\right)_{2} .6 \mathrm{H}_{2} \mathrm{O}$ and the appropriate amounts of $\mathrm{AgNO}_{3}$ were dissolved in distilled water and $50 \mathrm{ml}$ of solution were obtained. To this resulting $50 \mathrm{~mL}$ of the solution was added $37.5 \mathrm{mmol}$ of sodium hydroxide $(\mathrm{NaOH})$. This process was repeated to prepare five samples with SZO molar ratios of $0.0,0.5,1.0$ and $1.5 \%$. These solution samples were placed in a beaker and mixed using a magnetic stirrer. These blend samples were then transferred to teflon containers and placed in a microwave oven. The furnace was turned on and the mixtures were treated at $195{ }^{\circ} \mathrm{C}, 195 \mathrm{PSI}$ and 1 hour. After 1 hour the reaction was complete and 
the teflon containers were removed from the oven. Mixture samples were placed in filtration funnels for filtration and precipitates were collected by filtration. These precipitates were then washed with distilled water. Then, the obtained materials were placed in an oven and dried at $70^{\circ} \mathrm{C}$. These processed samples were then characterized for morphological, structural and DSSC applications.

\subsection{DSSC Fabrication}

The basic structure of DSSC is as shown in Fig. 1.

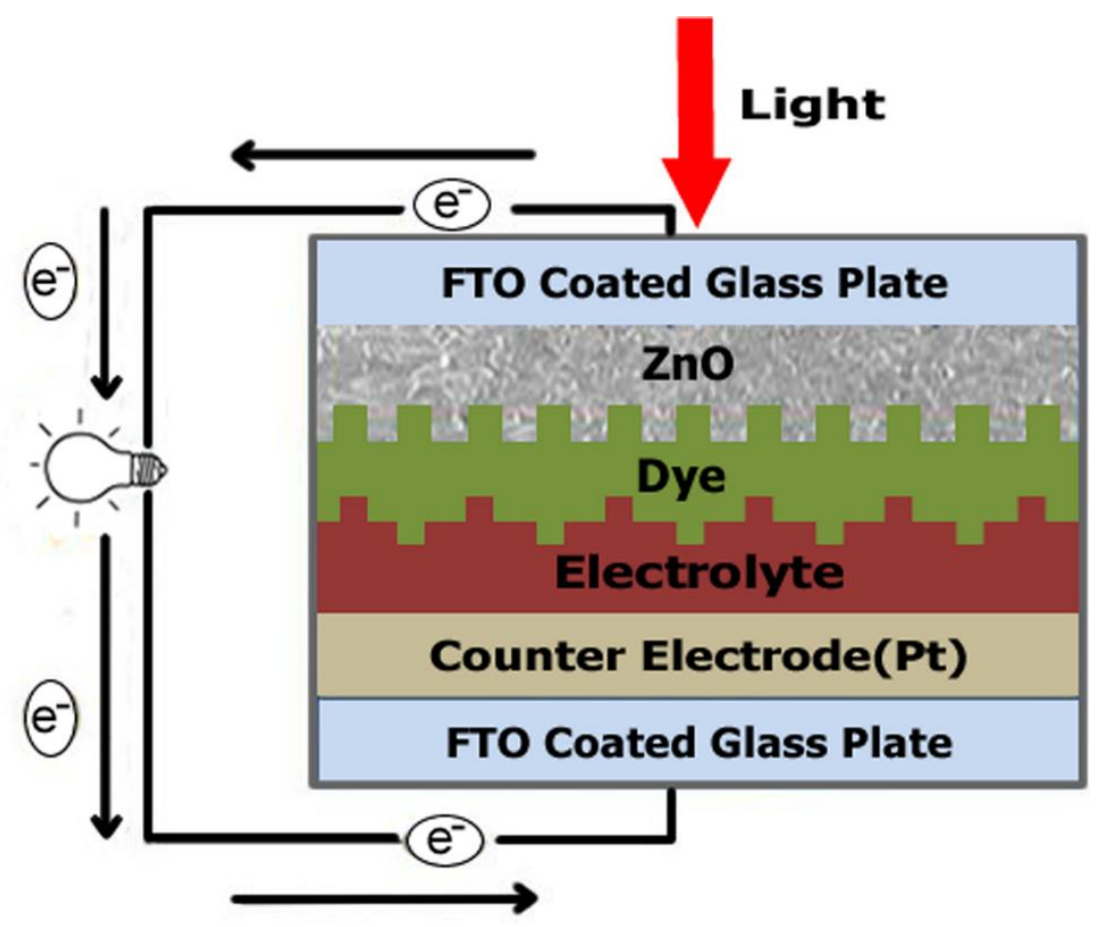

Fig. 1 The basic schematic design of ZnO nanomaterial based DSSC

DSSC starts working when sunlight hitting to the cell surface is absorbed by the dye adhere to the ZnO nanomaterial coated on the conductive glass (FTO or TCO). Light absorbing dye is induced and injects an electron from the valence band (VB) to the ZnO conduction band (CB). This electron passes through the nanocrystalline structure in $\mathrm{ZnO}$ to reach the photoanode. The electrolyte containing the redox couple neutralizes the dye cation. Then the electrolyte is reduced by electron from the coming external circuit. Finally, photocurrent occurs as a result of these electron movements and continues as long as the light comes on. During this operation, the net charge is always zero and chemically unchanged (Fig. 2-3). 


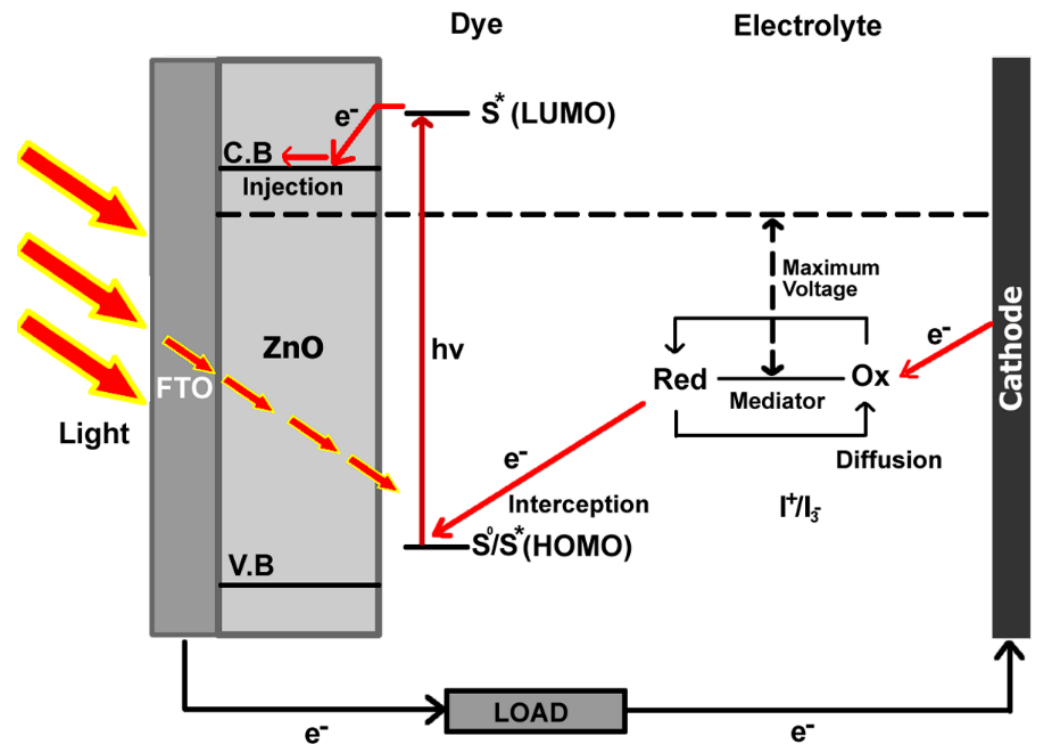

Fig. 2 Energy diagram and electron movement in a DSSC [21, 43]

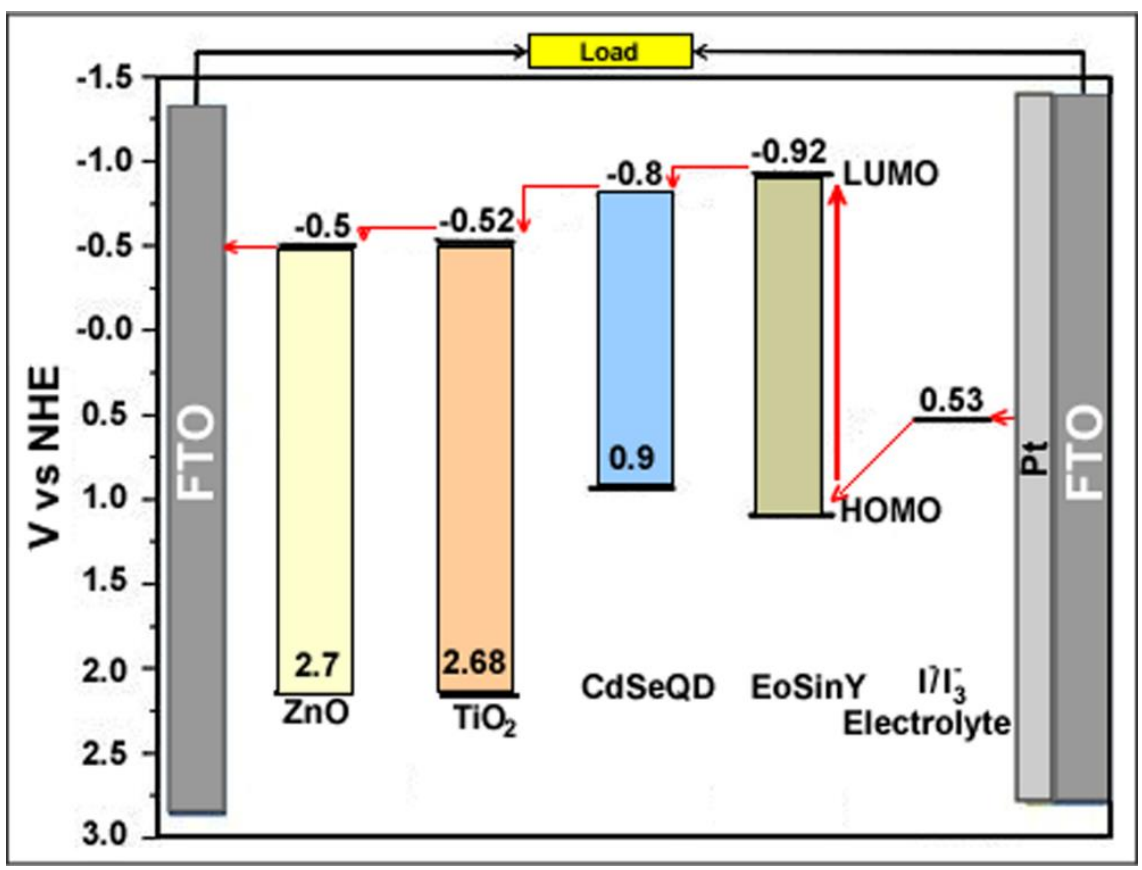

Fig. 3 Simplified energy level illustration and electron transmission of FTO/ZnODSSC [44]

In this solar cell fabrication, FTO (TEC 8; Hartford Glass) and TCO containing Solaronix, Platisolcatalyzed by platinum as counter electrode was used. An ethanol solvent was added to the SZO materials and SZO pastes were prepared using a dispermat. SZO coated 
FTO and TCO substrates were submerged in a $0.5 \mathrm{mM}$ solution of the Ruthenium complex of Z907 and N719 in ethanol overnight. Then SZO coated FTO and TCO substrates were dried. The active area of sell was 0.16 and $0.25 \mathrm{~cm}^{2}$. The cell was joined sandwich shape using a Surlyn. Then electrolyte was injected through pre-drilled hole and the hole was covered using a glass.

\section{Results and discussion}

\subsection{XRD Analysis of the SZO nanomaterials}

The XRD patterns of the synthesized SZO samples are as shown in Fig. 4.

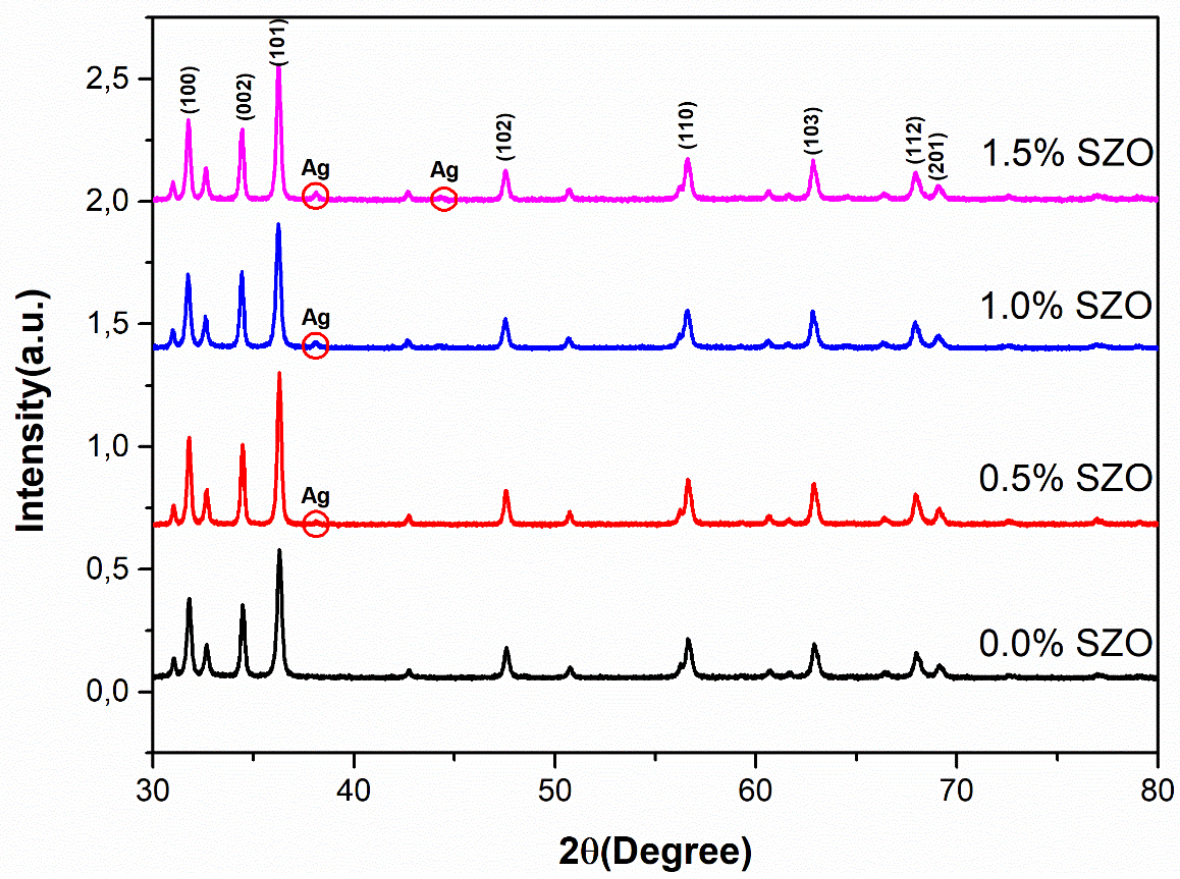

Fig. 4 The XRD patterns of the SZO samples with different $\mathrm{Ag} / \mathrm{Zn}$ molar ratio: $0.0 \% ; 0.5 \%$; $1.0 \% ; 1.5 \%$

All diffraction peaks of each sample were compared with the JCPDS card of $\mathrm{ZnO}$. It is seen that all of the peaks that match the result are in agreement with the data peaks. These results demonstrate the formation of synthesized SZO samples having a hexagonal wurzite structure. In other words these results showed that the as-synthesized SZO samples with a hexagonal wurtzite structure. The diffraction peaks positioned at $2 \theta$ values of $31.74,34.43,36.24,47.53,56.60,62.84,67.96,69.09^{\circ}$ can be indexed to the hexagonal wurtzite phase of zinc oxide (JCPDS card no. 36-1451). Furthermore the main peaks of SZO film correspond to the crystalline planes (100), (002), (101), (102), (110), (103), (112) and (201) at angles $31.74^{\circ}, 34.43^{\circ}, 36.24^{\circ}, 47.53^{\circ}, 56.60^{\circ}, 62.84^{\circ}, 67.96^{\circ}$, and $69.09^{\circ}$ respectively.In addition to the $\mathrm{ZnO}$ reflections, some small peaks were arosed corresponding to $\mathrm{Ag}$ at 38.15 and $44.3^{\circ}$ (red circle region) [45]. No other reflections weren't observed except for $\mathrm{ZnO}, \mathrm{Ag}$, and impurities in the pattern. 
The crystallites size $(D)$ was calculated from XRD data using Scherrer equation [46]:

$$
D=\frac{k \cdot \lambda}{\beta \cos \theta}
$$

Where, $D$ is crystallites size $(\mathrm{nm}), k$ is Scherrer constant, $\lambda$ is wavelength of the $\mathrm{x}$-ray sources, $\beta$ is FWHM (radians) and $\theta$ is peak position (radians).

From this XRD analysis, the average crystallite sizes corresponding to the undoped $\mathrm{ZnO}$ and doped $\mathrm{ZnO}$ with $0.5,1.0$ and $1.5 \mathrm{~mol} \%$ silver were $41,42,38$ and $37 \mathrm{~nm}$, respectively. The crystallite sizes of SZO nanoparticles are presented in Table 1.

Table 1.The crystallite sizes of SZO nanoparticles

\begin{tabular}{lc}
\hline \multicolumn{1}{c}{ Sample } & Average crystallite size (nm) \\
\hline $\mathbf{0 . 0} \%$ SZO & 41 \\
$\mathbf{0 . 5} \%$ SZ0 & 42 \\
$\mathbf{1 . 0 \%}$ SZ0 & 38 \\
$\mathbf{1 . 5 \%}$ SZ0 & 37 \\
\hline
\end{tabular}

Average crystallite size of undoped $\mathrm{ZnO}$ is $41 \mathrm{~nm}$, increases from $41 \mathrm{~nm}$ to $42 \mathrm{~nm}$ when $\mathrm{ZnO}$ is doped with $0.5 \%$ silver, and then decreases to 38 and $37 \mathrm{~nm}$ when doped $1.0 \%$ and $1.5 \%$ (Fig. 5).

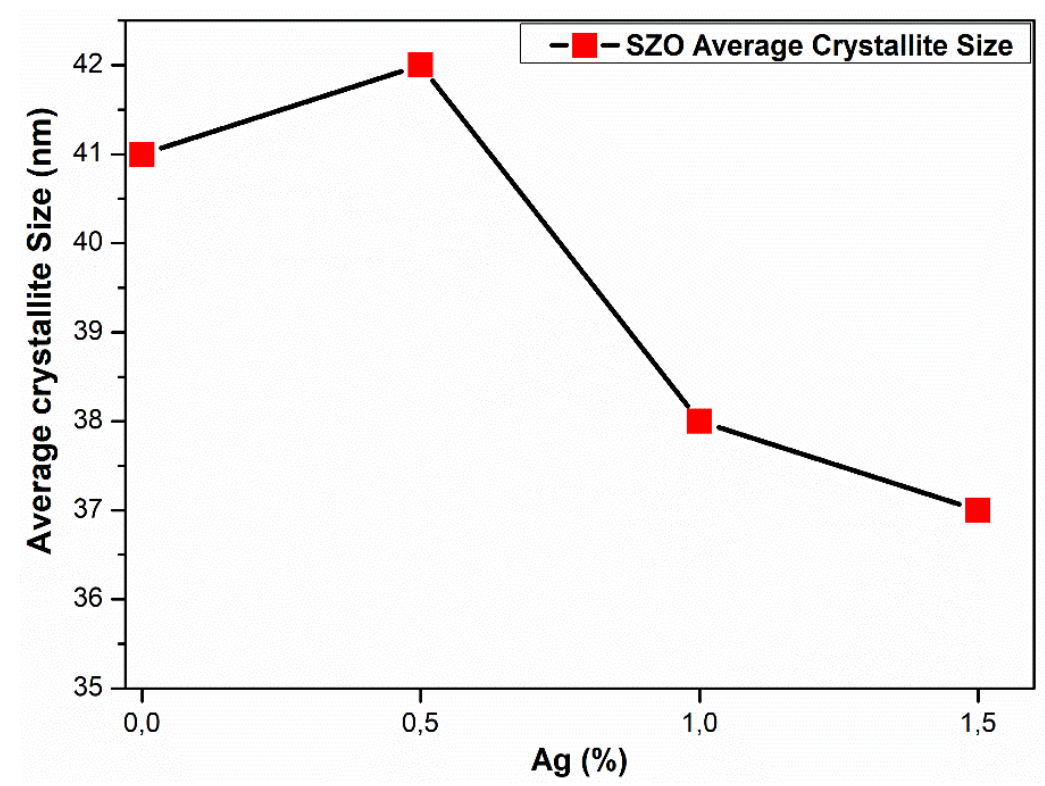

Fig. 5 Graph of the average crystallite sizes of SZO nanomaterials 


\subsection{SEM and EDX analysis of the SZO materials}

The structural morphologies of the SZO samples were investigated using SEM (Scanning Electron Microscopy) and the results are shown in Fig. 6(a-l). It was observed that the morphology of SZO samples changed partially and the ZnO nanorod length increased somewhat as the Ag doping ratio increased. Despite this increase, it was seen that the average crystal sizes first increased (Fig. 6d-f) and then decreased (Fig. 6g-l). There is good accordance between the values in Table 1 and the SEM images in Fig. 6.
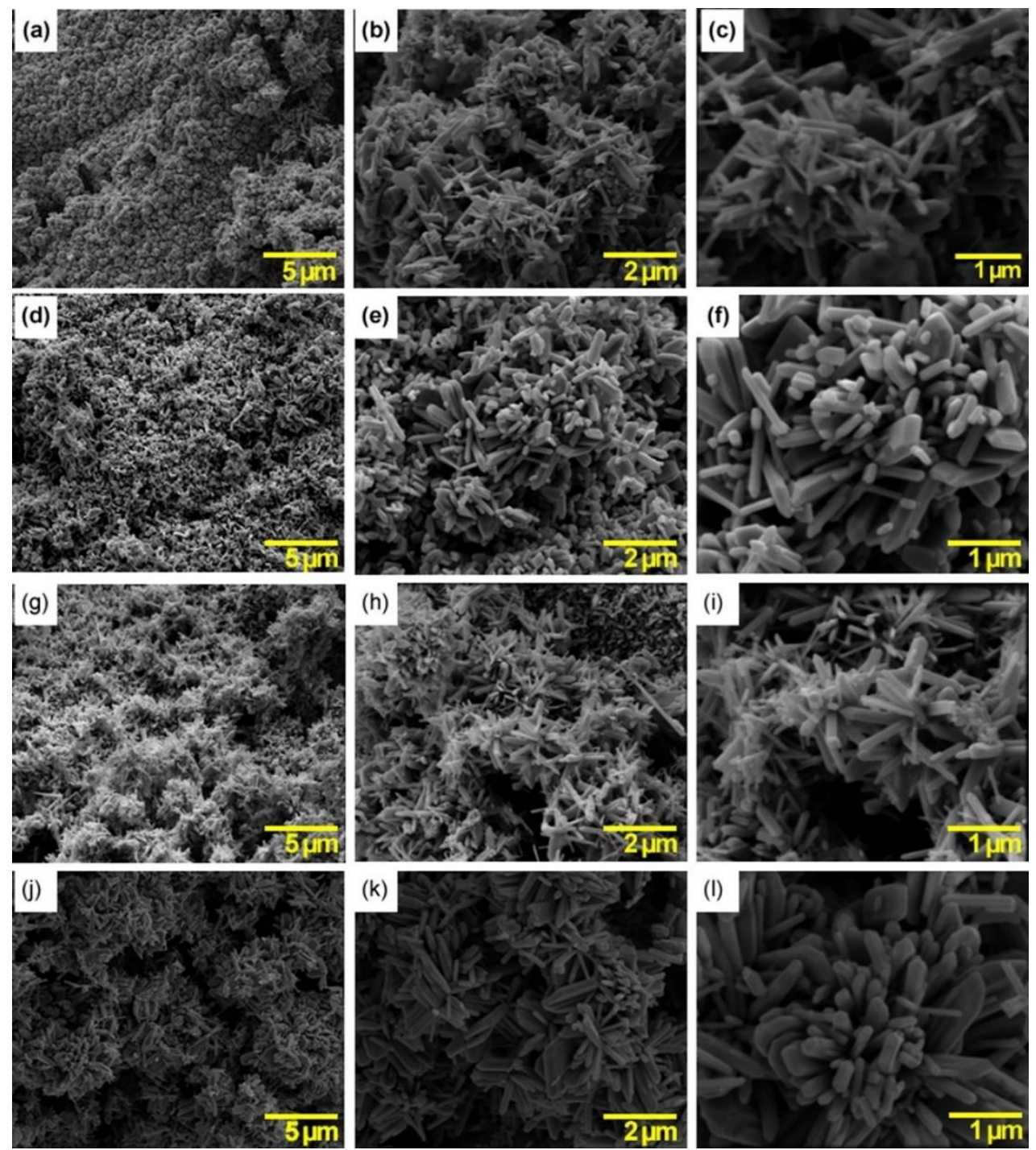

Fig. 6 (a) SEM İmages of 0.0\% SZO $(5 \mu \mathrm{m})$; (b) SEM İmages of $0.0 \%$ SZO $(2 \mu \mathrm{m})$; (c) SEM İmages of $0.0 \%$ SZO $(1 \mu \mathrm{m})$; (d) SEM İmages of $0.5 \%$ SZO $(5 \mu \mathrm{m})$; (e) SEM İmages of $0.5 \%$ SZO $(2 \mu \mathrm{m})$; (f) SEM İmages of $0.5 \%$ SZO $(1 \mu \mathrm{m})$; (g) SEM İmages of $1.0 \%$ SZO $(5 \mu \mathrm{m})$; (h) 
SEM İmages of 1.0\% SZO $(2 \mu \mathrm{m})$; (i) SEM İmages of 1.0\% SZO $(1 \mu \mathrm{m})$; (j) SEM İmages of $1.5 \%$ SZO $(5 \mu \mathrm{m})$; ( $\mathrm{k})$ SEM İmages of $1.5 \%$ SZO $(2 \mu \mathrm{m})$; (l) SEM İmages of 1.5\% SZO $(1 \mu \mathrm{m})$

The compositions and purity of SZO nanomaterials were investigated using energy dispersive X-ray (EDX) spectroscopy and the EDX spectra obtained were shown in Fig. 7 (a-d). When EDX spectra were examined, it was found that $\mathrm{Zn}, \mathrm{O}$ and $\mathrm{Ag}$ showed various well defined peaks. Furthermore, no peaks were detected for any foreign matter in the spectra. These results showed that the synthesized ZnOs were Ag-doped.
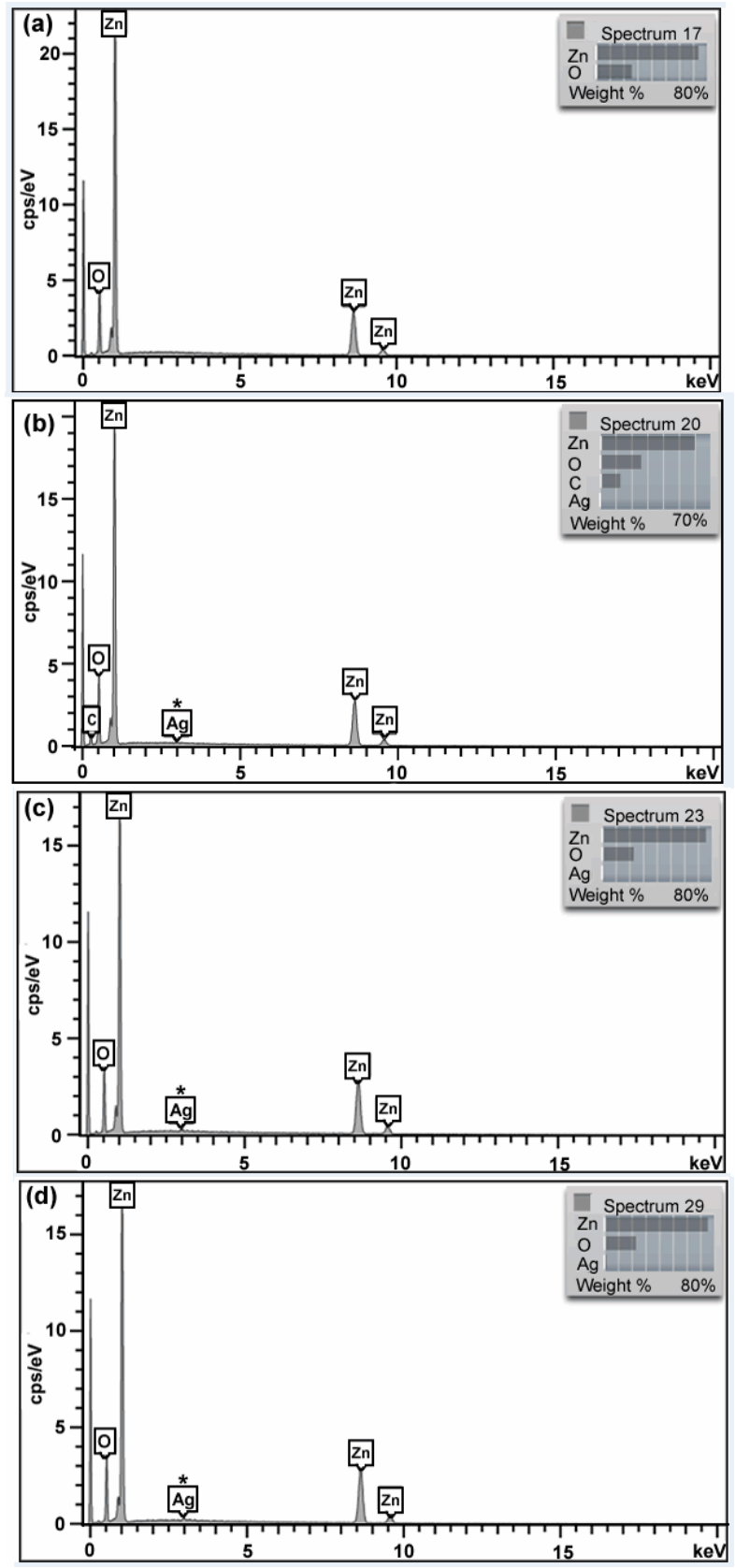
Fig. 7 The EDX images of the Ag-doped ZnO samples with different SZO molar ratio: (a) $0.0 \%$; (b) $0.5 \%$; (c) $1.0 \%$; (d) $1.5 \%$

\subsection{Optical properties}

Examination of optical properties of the SZO thin films have been performed using UVvisible spectroscopy and the results are shown in Fig. 8 and 9. The absorbance of SZO nanomaterials is in the range of $0.2-0.5 \%$ in the visible section of spectrum. The absorbsion of $0.0 \%$ SZO nanomaterial is in the range of $0.3-5 \%$ in the visible section of spectrum. On the other hand, when the Ag doping rate has increased the absorbance of SZO nanomaterials increased was observed (Fig. 8).

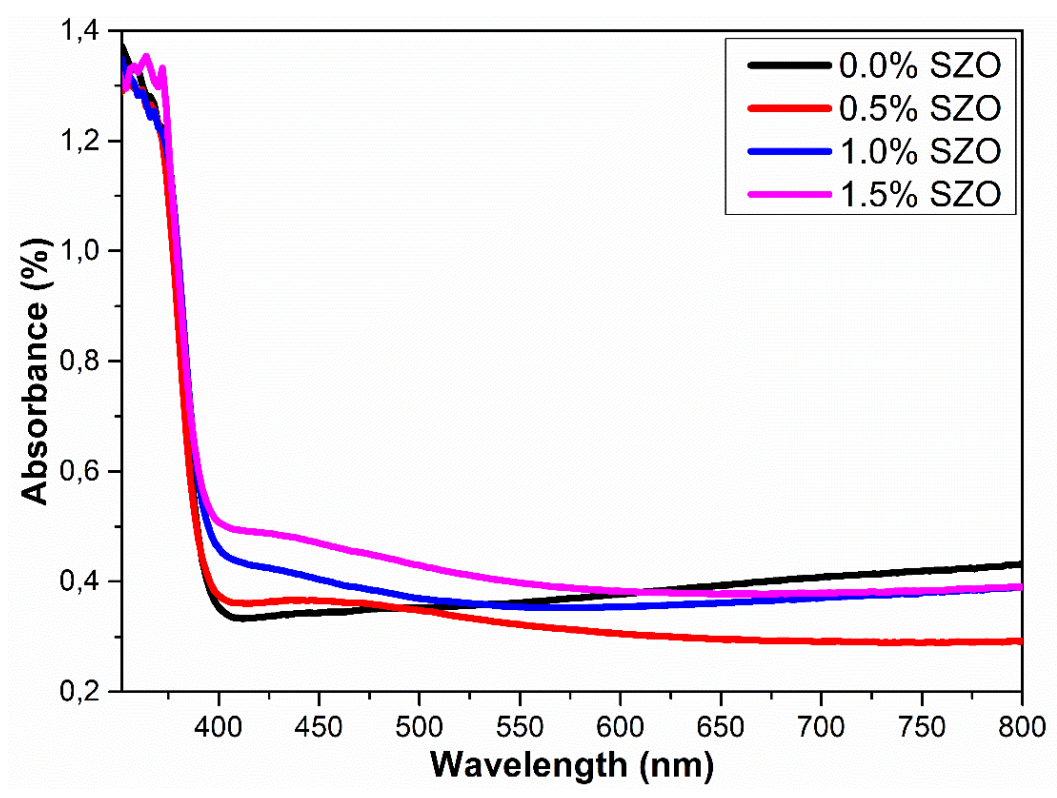

Fig. 8 Absorbance spectra of doped SZO nanomaterials

The transmission of SZO nanomaterials is in the range of $37-52 \%$ in the visible section of spectrum. The transmission of $0.0 \%$ SZO nanomaterial is in the range of $37-46 \%$ in the visible section of spectrum. Furthermore, when the Ag doping rate has increased the transmission of SZO nanomaterials decreased was observed (Fig. 9). 


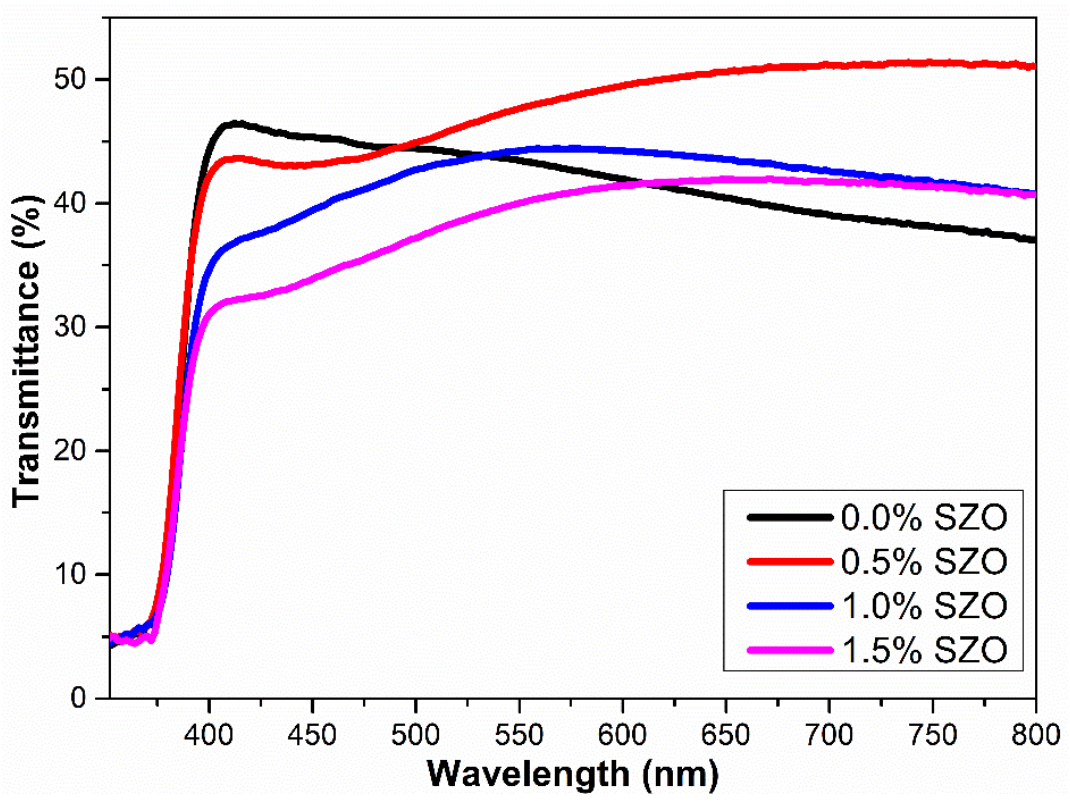

Fig. 9 UV-visible transmission spectra of SZO nanomaterials

Band gap variations of SZO nanomaterials are shown in Fig. 10. The band gap of the undoped $\mathrm{ZnO}$ and $0.5 \%, 1.0 \%$ and 1.5\% SZO nanomaterials are 3.19, 3.18, 3.16 and 3.19 $\mathrm{eV}$, respectively. It was observed that the band gap decreased when doping $0.5 \%$ and $1.0 \%$, and increased when doping $1.5 \%$. The reason for the narrowing of the band gap with Ag doping may be the displacement of $\mathrm{Ag}^{2+}$ and $\mathrm{Zn}^{2+}$ [47].

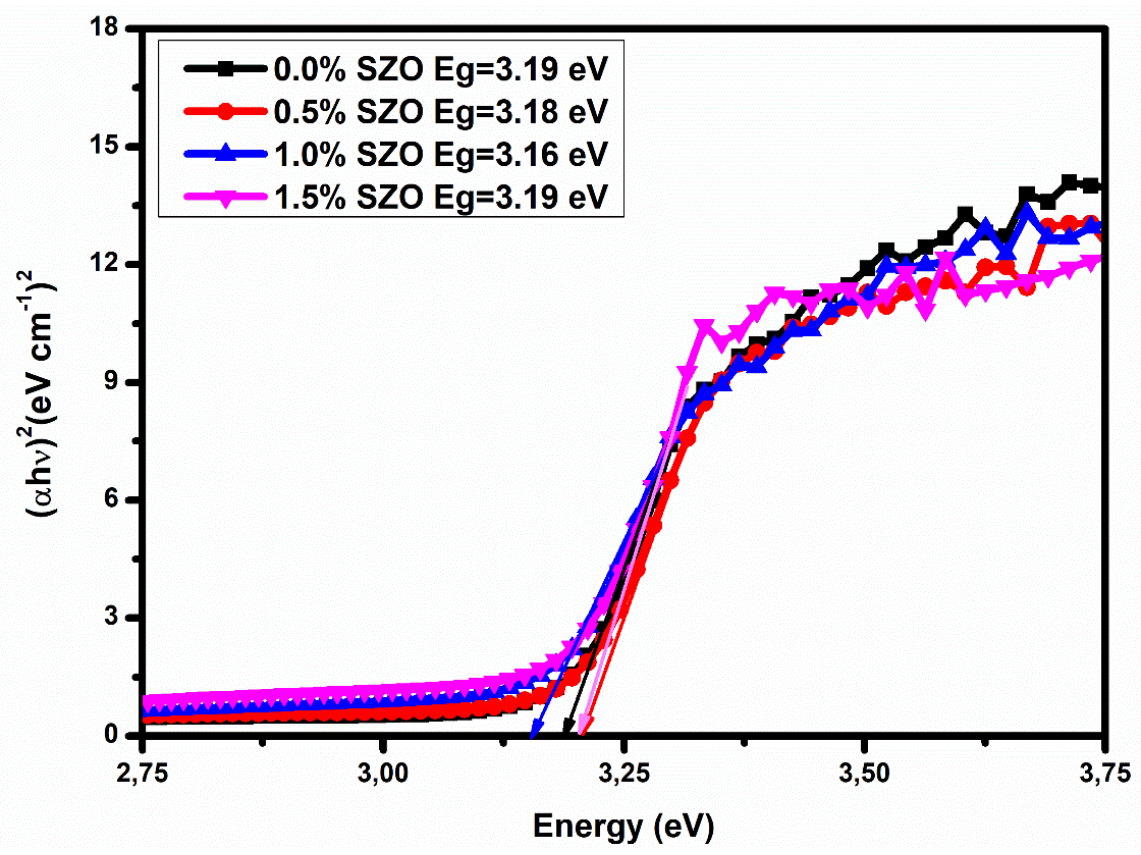

Fig. 10 Band gap variations in SZO nanomaterials 


\subsection{Photovoltaic Performances of DSSCs}

The fill factor (FF) and efficiency ( $\eta$ ) values of each cell were calculated using the following equations:

$$
\begin{aligned}
& F F=\frac{I m \cdot V m}{I s c \cdot V o c} \\
& \eta=\frac{I s c \cdot V o c \cdot F F}{S . G t}
\end{aligned}
$$

Where, $\mathrm{I}_{\mathrm{m}}$ is maximal current, $\mathrm{V}_{\mathrm{m}}$ maximal voltage, Isc is short circuit current, $\mathrm{V}_{\text {oc }}$ is open circuit voltage, $\mathrm{S}$ is the surface area of the cell and Gt is the incident light density.

\subsubsection{Photovoltaic performances of DSSCs fabricated using Z907 dye}

The photocurrent density-photovoltage $(\mathrm{J}-\mathrm{V})$ and incident photon to current conversion efficiency (IPCE) of DSSCs fabricated using Z907 dye based on SZO nanomaterials were exhibited in Fig. (11-12) and their photovoltaic characterization is summarized in Table 2. IPCE of $0.5 \%$ SZO based DSSC showed $13 \%$ efficiency at $500 \mathrm{~nm}$ in Fig. 12. The fill factor of $0.0 \%$ SZO, $0.5 \%$ SZO, $1.0 \%$ SZO and $1.5 \%$ SZO are $0.32,0.56,0.56$ and 0.51 , respectively. The current density was affected by the doping concentration. The calculated efficiency of the DSSCs with ZnO photoanode doped with 0.0, 0.5, 1.0 and $1.5 \mathrm{~mol} \%$ of Ag are $0.005 \%, 0.51 \%, 0.46 \%$ and $0.22 \%$, respectively. Under the standard global AM 1.5 solar irradiation, $0.0 \%$ SZO based DSSC gave a short circuit current density $\left(U_{\mathrm{sc}}\right)$ of $0.13 \mathrm{~mA} / \mathrm{cm}^{2}$, open circuit voltage $\left(V_{\text {oc }}\right)$ of $100 \mathrm{mV}$, and a fill factor of 0.31 , corresponding to an overall conversion efficiency of 0.005 . When the $0.0 \%$ SZO was doped with $0.5 \% \mathrm{Ag}$, band gap narrowed and dropped from $3.19 \mathrm{eV}$ to $3.18 \mathrm{eV}$. This reduction in energy gap led to the increased efficiency in the use of this material in DSSC device [48]. Furthermore, the average crystallite sizes increased from $41 \mathrm{~nm}$ to $42 \mathrm{~nm}$ and surface area increased for dye adhering. Then more dye was adhered to the crystals and thus more light was absorbed by dye. Consequently, short circuit current density increased from $0.13 \mathrm{~mA} / \mathrm{cm}^{2}$ to $1.88 \mathrm{~mA} / \mathrm{cm}^{2}$, open circuit voltage from $100 \mathrm{mV}$ to $500 \mathrm{~V}$, fill factor from 0.31 to 0.56 , and efficiency from 0.005 to 0.51 . Subsequently, when the $0.0 \%$ SZO was doped with $1.0 \%$ and $1.5 \%$ Ag the average crystallite sizes decreased from $42 \mathrm{~nm}$ to $38 \mathrm{~nm}$ and $37 \mathrm{~nm}$. This resulted in less dye adherence and therefore less light absorption. In addition, the performance of DSSC decreased as the light reaching the dye decreased due to the increase in absorbance and decrease in transmittance (Fig. 8-9). For this reason, it was observed that the short-circuit current density decreased from 1.88 $\mathrm{mA} / \mathrm{cm}^{2}$ to $1.66 \mathrm{~mA} / \mathrm{cm}^{2}$ and $0.88 \mathrm{~mA} / \mathrm{cm}^{2}$, the efficiency from 0.51 to 0.46 and 0.22 .

As a result, 0.5\% SZO nanomaterial based DSSC fabricated using Z907 dye was showed the best performance. 


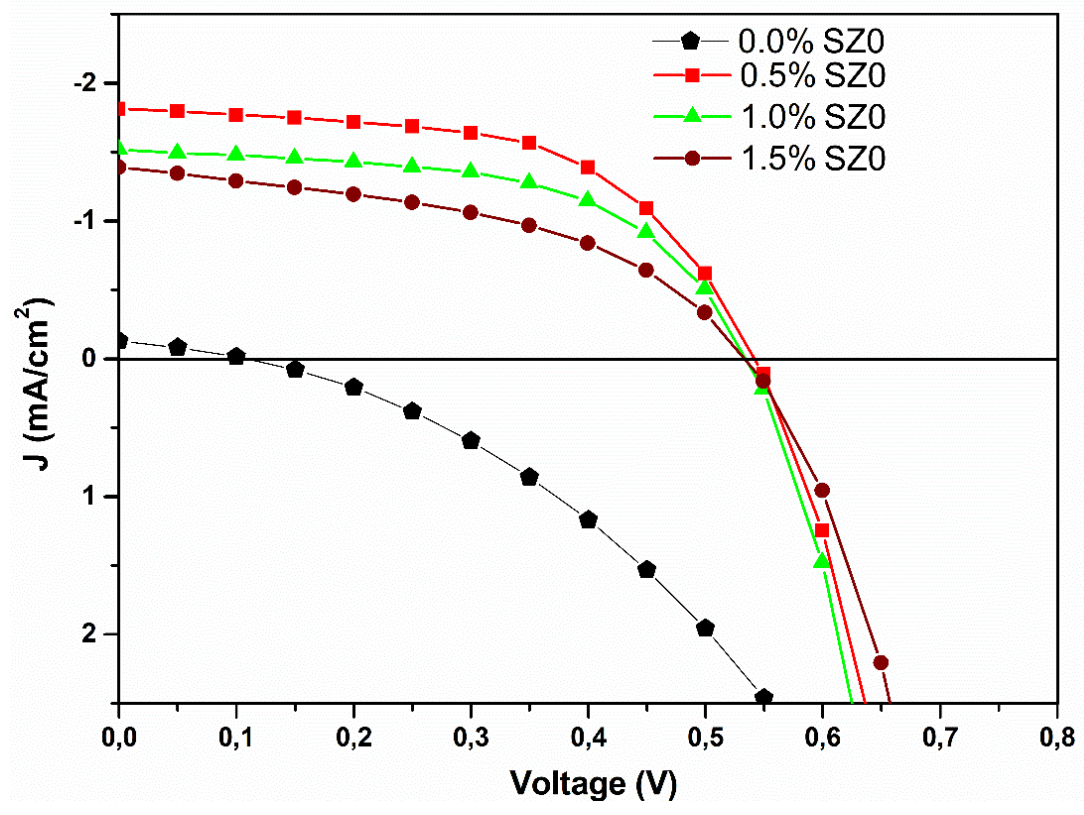

Fig. $11 \mathrm{~J}-\mathrm{V}$ curve of DSSC fabricated using Z907 dye under illumination

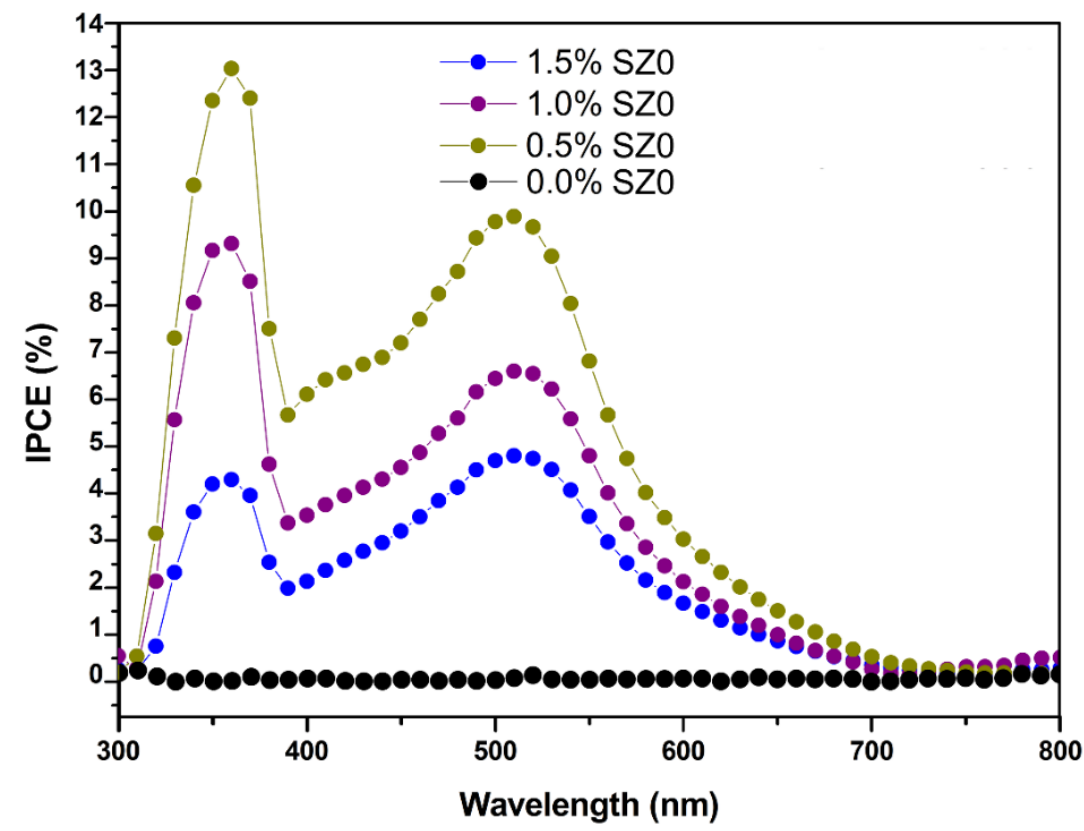

Fig. 12 Incident Photon to Charge Carrier Efficiency (IPCE) curve of DSSC fabricated using Z907 dye 
Table 2.Photovoltaic Performance of SZO based DSSCs fabricated using Z907 dye

\begin{tabular}{lcccc}
\hline Sample & $\mathbf{J}_{\mathbf{s c}}\left(\mathbf{m A c m}^{-2}\right)$ & $\mathbf{V}_{\text {oc }}(\mathbf{m V})$ & FF & $\eta(\%)$ \\
\hline $\mathbf{0 . 0} \%$ SZ0 & 0,13 & 100 & 0,32 & 0,005 \\
\hline $\mathbf{0 . 5 \%}$ SZO & 1.88 & 500 & 0.56 & 0.51 \\
\hline $\mathbf{1 . 0} \%$ SZ0 & 1.66 & 500 & 0.56 & 0.46 \\
\hline $\mathbf{1 . 5 \%}$ SZ0 & 0.88 & 500 & 0.51 & 0.22 \\
\hline
\end{tabular}

\subsubsection{Photovoltaic performances of DSSCs fabricated using N719 dye}

The photocurrent density-photovoltage and incident photon to current conversion efficiency of DSSCs fabricated using N719 dye based on SZO nanomaterials were exhibited in Fig. (14-15) and their photovoltaic characterization is summarized in Table 3. The lowest unoccupied molecular orbital (LUMO) level of N719 dye is higher than the conduction band of $\mathrm{ZnO}$ nanomaterials [49,50]. This facilitates electron transfer from N719 to the ZnO nanomaterial surface. The cascading energy levels of the DSSC material components are shown in Fig. 13.

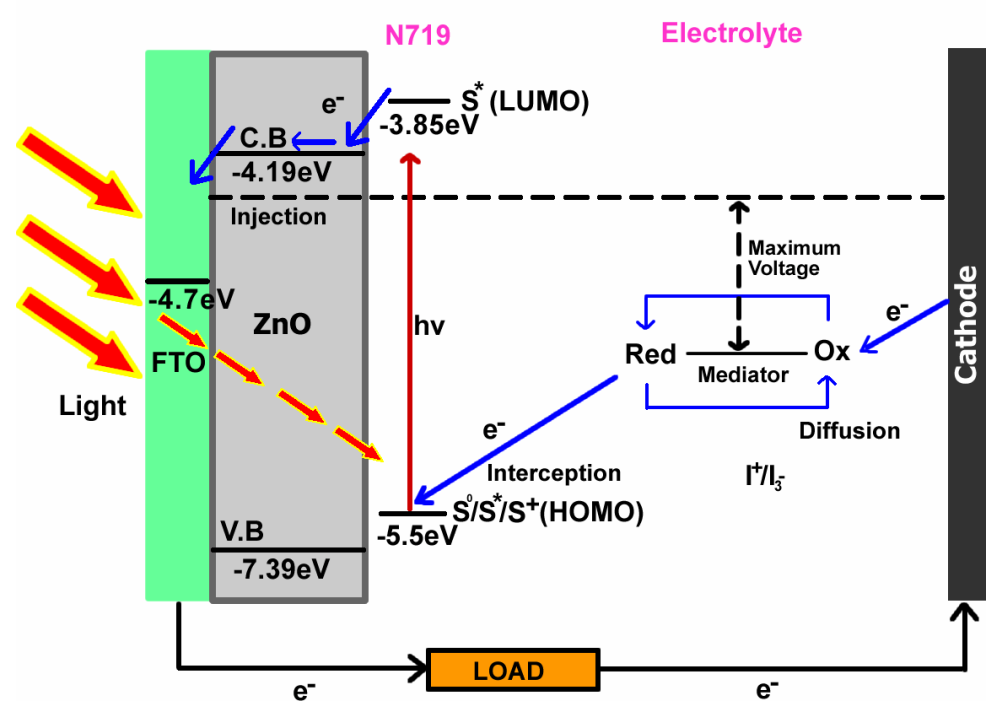

Fig. 13 Energy level diagram of the FTO/ZnO/N719/Electrolyte/Pt/FTO device

N719 dye molecules are chemically bonded to $\mathrm{ZnO}$ nanomaterials. This structure occurs the formation of cascading energy levels that lead to easy electron flow from the N719 dye to ZnO (Fig. 13). N719 dye absorbs the photon of light hitting the cell surface and creates an electron hole pair. This electron efficiently transfers from the LUMO level of the N719 dye to the conduction band of ZnO nanomaterials, and from there it reaches the conductive glass FTO. It is then transmitted to the counter electrode via the external circuit. Thus, under illumination the DSSC creates a regenerative and stable photovoltaic energy conversion mechanism (Eq. 1-4)[51]. Firstly photon is absorbed by sensitizer 
(N719 (S)) (Eq. 4) Then the electron is transferred to the conduction band of ZnO. Injected electron to conduction band of $\mathrm{ZnO}$ leads to excitation of sensitizer $\left(\mathrm{S}^{*}\right)$ and leaves sensitizer in oxidized state $\left(\mathrm{S}^{+}\right)$(Eq. 5). The injected electron flows through the semiconductor network to reach the back contact and then flows through the external charge to the counter electrode to reduce the redox mediator (Eq. 6), which regenerates the sensitizer (Eq. 7). This completes the circuit mechanism [51].

$$
\begin{aligned}
& S_{(\text {absorbed })}+h v \rightarrow S_{(\text {absorbed })}^{*} \\
& S_{(\text {absorbed })}^{*} \rightarrow S_{(\text {absorbed })}^{+}+e_{(\text {injected })}^{-} \\
& I_{3}^{-}+2 \cdot e_{(\text {cathode })}^{-} \rightarrow 3 I_{(\text {cathode })}^{-} \\
& S_{(\text {absorbed })}^{+}+\frac{3}{2} I^{-} \rightarrow S_{(\text {absorbed })}+\frac{1}{2} I_{3}^{-}
\end{aligned}
$$

N719 dye molecules fitted between $\mathrm{ZnO}$ nanoparticles increase the efficiency of solar cells by increasing charge transfer and decreasing charge recombination. In addition, in literature, it was reported that the interaction between ZnO nanorod and N719 is high, which leads to a better charge transfer[52]. Furthermore, it was reported that the distance between the N719 dye skeleton and the point attached to the ZnO surface is narrow, and therefore, better performance can be obtained by facilitating an electron transfer from N719 to the surface of $\mathrm{ZnO}$ nanorod arrays [52].

IPCE of $0.5 \%$ SZO based DSSC showed $2.7 \%$ efficiency at $525 \mathrm{~nm}$ in Fig. 15. The calculated efficiency of the DSSCs with ZnO photoanode doped with $0.0,0.5,1.0$ and $1.5 \mathrm{~mol} \%$ of $\mathrm{Ag}$ are $0.06 \%, 0.17 \%, 0.07 \%$ and $0.06 \%$, respectively. SZO nanomaterials showed due to the above-mentioned properties the same effect in this DSSC device as it affected DSSC fabricated using Z907 dye, and it was observed that DSSC based on $0.5 \%$ SZO nanomaterial fabricated using N719 dye showed higher performance than others. Although efficiency values are low the change in efficiency rate is remarkable when the doping concentration changes. The results of similar type of study in literature, reported that $0.5 \%$ Ag-doped ZnO showed the highest efficiency [45]. 


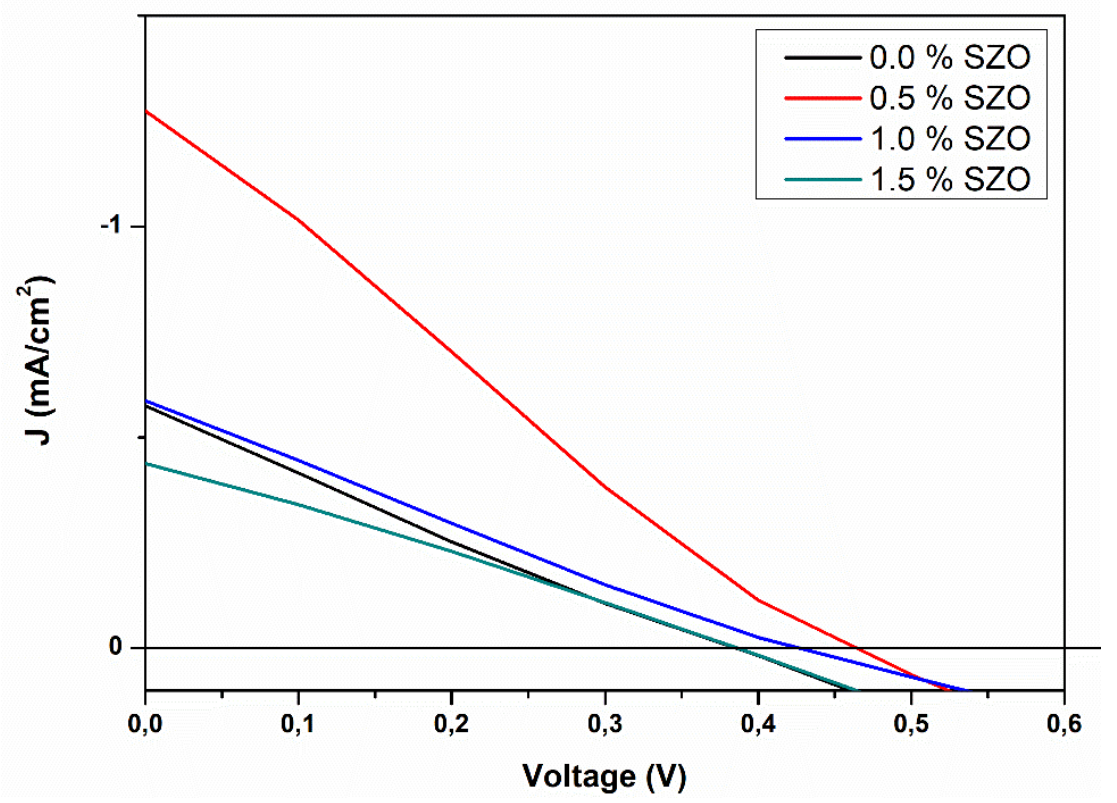

Fig. $14 \mathrm{~J}-\mathrm{V}$ curve of DSSC fabricated using N719 dye under illumination

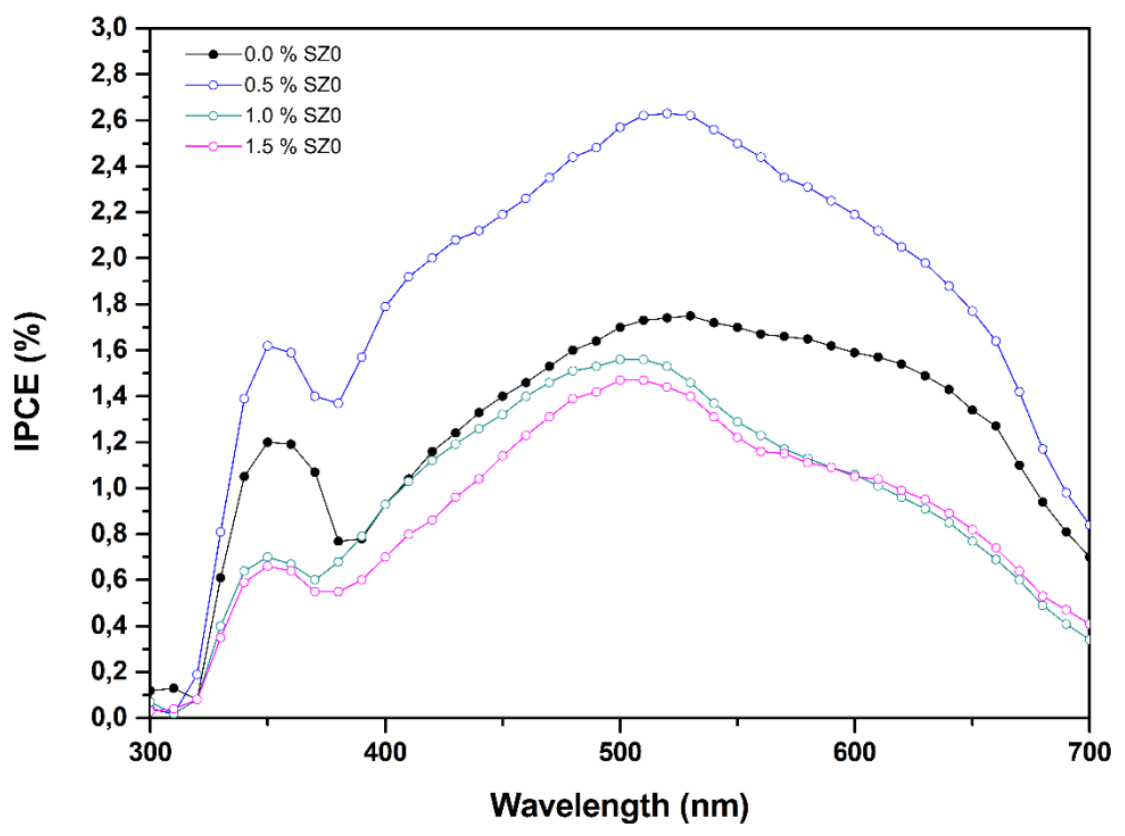

Fig. 15 Incident Photon to Charge Carrier Efficiency (IPCE) curve of DSSC fabricated using N719 dye 
Table 3. Photovoltaic Performance of SZO based DSSCs fabricated using N719 dye

\begin{tabular}{|c|c|c|c|c|}
\hline Sample & Jsc $\left(\mathrm{mAcm}^{-2}\right)$ & Voc $(\mathrm{mV})$ & FF & $\eta(\%)$ \\
\hline $0.0 \%$ SZO & 0,61 & 400 & 0,21 & 0,06 \\
\hline $0.5 \%$ SZO & 1,27 & 500 & 0,22 & 0,17 \\
\hline $1.0 \% \mathrm{SZO}$ & 0,59 & 400 & 0,25 & 0,07 \\
\hline $1.5 \%$ SZO & 0,46 & 400 & 0,27 & 0,06 \\
\hline
\end{tabular}

\section{Conclusion}

- The aim of the present research was to synthesize the Ag-doped ZnO nanomaterials (SZO) for DSSCs and investigate the optimum ratio of Ag doping.

- SZO nanomaterials were successfully synthesized using the hydrothermal production method with doping concentrations of $0.0,0.5,1.0$, and $1.5 \% \mathrm{Ag}$ and fully characterized by XRD, SEM and EDX analysis.

- The structural analysis confirmed the formation of synthesized SZO samples having a hexagonal $\mathrm{ZnO}$ wurtzite phase.

- Further examines also have revealed a change in crystal structure when the doping concentration of silver increased.

- The morphology of SZO samples changed partially and the ZnO nanorod length increased somewhat as the Ag doping ratio increased.

- Despite this increase, it was seen that the average crystal sizes first increased and then decreased. The crystallite sizes calculated from XRD data for 0.0, 0.5, 1.0 and $1.5 \mathrm{~mol} \%$ SZO were obtained as 41, 42, 38 and $37 \mathrm{~nm}$, respectively.

- Ag doping concentration has increased the absorbance of SZO nanomaterials increased and the transmission decreased was observed.

- The band gap of the $0.0 \%, 0.5 \%, 1.0 \%$ and $1.5 \%$ SZO nanomaterials were measured $3.19,3.18,3.16$ and $3.19 \mathrm{eV}$, respectively. Two types of SZO based DSSC were fabricated using Z907 and N719 dyes and investigated their photovoltaic performances.

- The calculated efficiencies of DSSCs fabricated using Z907 dye for $0.0 \%, 0.5 \%, 1.0 \%$ and $1.5 \%$ SZO were $0.005,0.51,0.46$ and $0.22 \%$, respectively.

- Then the calculated efficiencies of DSSCs fabricated using N719 dye for $0.0 \%, 0.5 \%$, $1.0 \%$ and $1.5 \%$ SZO were $0.06,0.17,0.07$ and $0.06 \%$, respectivelyIn both studies and above mentioned similar study in literature, DSSCs with ZnO film doped with $0.5 \%$ SZO showed higher photovoltaic performance as compared to other DDSC samples.

- The results of this investigation show that the optimum ratio of Ag doping is $0.5 \%$.

\section{Acknowledgement}

This article is produced from "Automation and control test at hot water pipe, production of zinc oxide ( $\mathrm{ZnO})$ solar cell" titled master thesis. We acknowledged financial and working support from The Scientific and Technological Research Council of Turkey (TUBITAK), Uşak University, Ege University, material support from Yorglass Company. 


\section{References}

1. O'Regan, B. and Grätzel M. A Low-Cost, High-Efficiency Solar Cell Based on DyeSensitized Colloidal TiO2 Films. Nature. 1991;353:737-740.

2. Acikgoz S, Ulusu Y, Akin S, Sonmezoglu S, Gokce I, Inci MN. Photoinduced electron transfer mechanism between green fluorescent protein molecules and metal oxide nanoparticles. Ceram Int. 2014;40(2):2943-2951. Elsevier,

3. Cao G. Nanostrucrures \& Nanomaterials. Univ Washingt. Published online 2005.

4. Sass J. Nanotechnology's Invisible Threat Small Science, Big Consequences. Nat Resour Def Counc. Published online 2007.

5. Acikgoz S, Ulusu Y, Akin S, Sonmezoglu S, Gokce I, Inci MN. Photoinduced electron transfer mechanism between green fluorescent protein molecules and metal oxide nanoparticles. Ceram Int. 2014;40(2):2943-2951. Elsevier,

6. Tas R, Can M, Sonmezoglu S. Exploring on Photovoltaic Performance of DyeSensitized Solar Cells Using Polyaniline as a Counter Electrode: Role of Aluminum-Solvent Interactions. IEEE J Photovoltaics. 2017;7(3):792-801. IEEE,

7. Gulen M, Sarilmaz A, Patir IH, Ozel F, Sonmezoglu S. Ternary copper-tungstendisulfide nanocube inks as catalyst for highly efficient dye-sensitized solar cells. Electrochim Acta. 2018;269:119-127. Elsevier Ltd,

8. Ateş Sönmezoğlu Ö, Akın S, Terzi B, Mutlu S, Sönmezoğlu S. An Effective Approach for High-Efficiency Photoelectrochemical Solar Cells by Using Bifunctional DNA Molecules Modified Photoanode. Adv Funct Mater. 2016;26(47):8776-8783.

9. Al-Hadeethi Y, Umar A, Ibrahim AA, et al. Synthesis, characterization and acetone gas sensing applications of Ag-doped $\mathrm{ZnO}$ nanoneedles. Ceram Int. 2017;43(9):6765-6770.

10. Pat S, Mohammadigharehbagh R, Özen S, Şenay V, Yudar HH, Korkmaz Ş. The Al doping effect on the surface, optical, electrical and nanomechanical properties of the $\mathrm{ZnO}$ and AZO thin films prepared by RF sputtering technique. Vacuum. 2017;141:210-215.

11. Look DC. Recent advances in $\mathrm{ZnO}$ materials and devices. Mater Sci Eng B SolidState Mater Adv Technol. 2001;80(1-3):383-387.

12. Sohn S, Soo Y. Transparent Conductive Oxide (TCO) Films for Organic Light Emissive Devices (OLEDs). Org Light Emit Diode - Mater Process Devices. Published online 2011.

13. Jafarzadeh M, Sipaut CS, Dayou J, Mansa RF. Recent progresses in solar cells: Insight into hollow micro/nano-structures. Renew Sustain Energy Rev. 2016;64:543-568. Elsevier,

14. Krämer A, Engel S, Sangiorgi N, et al. ZnO thin films on single carbon fibres fabricated by Pulsed Laser Deposition (PLD). Appl Surf Sci. 2017;399:282-287. Elsevier B.V.,

15. Nandi R, Major SS. The mechanism of growth of $\mathrm{ZnO}$ nanorods by reactive sputtering. Appl Surf Sci. 2017;399:305-312. Elsevier B.V.,

16. Tzou AJ, Chien KF, Lai HY, et al. The study of self-assembled ZnO nanorods grown on $\mathrm{Si}(111)$ by plasma-assisted molecular beam epitaxy. J Cryst Growth. 2013;378:466-469.

17. Sokovnin SY, Il'ves VG, Khrustov VR, Zuev MG. Investigation of properties of ZnO ceramics sintered from $\mathrm{ZnO}-\mathrm{Zn}$ nanopowders produced by pulsed electron beam evaporation. Ceram Int. 2017;43(14):10637-10644. Elsevier Ltd and Techna Group S.r.l.,

18. Meléndrez MF, Solis-Pomar F, Gutierrez-Lazos CD, et al. A new synthesis route of $\mathrm{ZnO}$ nanonails via microwave plasma-assisted chemical vapor deposition. Ceram Int. 2016;42(1):1160-1168. Elsevier, 
19. Erten-Ela S, Cogal S, Icli S. Conventional and microwave-assisted synthesis of ZnO nanorods and effects of PEG400 as a surfactant on the morphology. Inorganica Chim Acta. 2009;362(6):1855-1858. Elsevier B.V.,

20. Hasnidawani JN, Azlina HN, Norita H, Bonnia NN, Ratim S, Ali ES. Synthesis of ZnO Nanostructures Using Sol-Gel Method. Procedia Chem. 2016;19:211-216. Elsevier Ltd.,

21. Ekmekci M, Ela C, Erten-Ela S. Morphological characterization of aluminumdoped zinc oxide nanomaterials (AZO) for dye-sensitized solar cells. Int J Appl Ceram Technol. 2019;16(2):727-734.

22. Premkumar T, Zhou YS, Gao Y, Baskar K, Jiang L, Lu YF. Morphological transition of $\mathrm{ZnO}$ nanostructures influenced by magnesium doping. Appl Surf Sci. 2012;258(7):2297-2300.

23. Bernardo MS, Villanueva PG, Jardiel T, Calatayud DG, Peiteado M, Caballero AC. Ga-doped ZnO self-assembled nanostructures obtained by microwave-assisted hydrothermal synthesis: Effect on morphology and optical properties. J Alloys Compd. 2017;722:920-927. Elsevier B.V,

24. Akin S, Erol E, Sonmezoglu S. Enhancing the electron transfer and band potential tuning with long-term stability of $\mathrm{ZnO}$ based dye-sensitized solar cells by gallium and tellurium as dual-doping. Electrochim Acta. 2017;225:243-254. Elsevier Ltd,

25. Wu SP, Zhao QY, Zheng LQ, Ding XH. Behaviors of ZnO-doped silver thick film and silver grain growth mechanism. Solid State Sci. 2011;13(3):548-552.

26. Kanimozhi G, Vinoth S, Kumar H, Srinadhu ES, Satyanarayana N. Electrospun Nanocomposite Ag-ZnO Nanofibrous Photoanode for Better Performance of DyeSensitized Solar Cells. J Electron Mater. 2019;48(7):4389-4399. Springer New York LLC,

27. Nguyen Q, Kwon JW. Silver nanowire-based transparent electrode as FTO replacement for dye-sensitized solar cell. Int Nano Lett. 2019;9(1):83-87. Springer Science and Business Media LLC,

28. Coşkun B. Investigation of dielectric properties of Ag-doped $\mathrm{ZnO}$ thin films. J Mol Struct. 2020;1209.

29. Liu WS, Wu SY, Hung CY, Tseng CH, Chang YL. Improving the optoelectronic properties of gallium $\mathrm{ZnO}$ transparent conductive thin films through titanium doping. J Alloys Compd. 2014;616:268-274. Elsevier B.V.,

30. Kadam AN, Kim TG, Shin DS, Garadkar KM, Park J. Morphological evolution of Cu doped $\mathrm{ZnO}$ for enhancement of photocatalytic activity. J Alloys Compd. 2017;710:102-113. Elsevier B.V,

31. Wan X, Liang X, Zhang C, et al. Morphology controlled syntheses of Cu-doped ZnO, tubular $\mathrm{Zn}(\mathrm{Cu}) \mathrm{O}$ and $\mathrm{Ag}$ decorated tubular $\mathrm{Zn}(\mathrm{Cu}) \mathrm{O}$ microcrystals for photocatalysis. Chem Eng J. 2015;272:58-68. Elsevier B.V.,

32. Sönmezołlu S, Akman E. Improvement of physical properties of $\mathrm{ZnO}$ thin films by tellurium doping. Appl Surf Sci. 2014;318:319-323.

33. Murugadoss G. Synthesis and Characterization of Transition Metals Doped ZnO Nanorods. J Mater Sci Technol. 2012;28(7):587-593. The Chinese Society for Metals,

34. Ahmad M, Ahmad I, Ahmed E, Akhtar MS, Khalid NR. Facile and inexpensive synthesis of Ag doped ZnO/CNTs composite: Study on the efficient photocatalytic activity and photocatalytic mechanism. J Mol Liq. 2020;311:113326. Elsevier B.V.,

35. Soumya S, Sheemol VN, Amba P, Mohamed AP, Ananthakumar S. Sn and Ag doped ZnO quantum dots with PMMA by in situ polymerization for UV/IR protective, photochromic multifunctional hybrid coatings. Sol Energy Mater Sol Cells. 2018;174(June 2017):554-565. Elsevier B.V.,

36. Rakhsha AH, Abdizadeh H, Pourshaban E, Golobostanfard MR, Mastelaro VR, 
Montazerian M. Ag and $\mathrm{Cu}$ doped $\mathrm{ZnO}$ nanowires: A pH-Controlled synthesis via chemical bath deposition. Materialia. 2019;5(January). Elsevier Ltd,

37. Cakir AC, Erten-Ela S. Comparison between synthesis techniques to obtain ZnO nanorods and its effect on dye sensitized solar cells. Adv Powder Technol. 2012;23(5):655-660. The Society of Powder Technology Japan,

38. Erten-Ela S. Photovoltaic performance of $\mathrm{ZnO}$ nanorod and $\mathrm{ZnO}$ : $\mathrm{CdO}$ nanocomposite layers in dye-sensitized solar cells (DSSCs). Int J Photoenergy. 2013;2013.

39. Padmavathy V, Sankar S. Influence of rare earth (La and Y) codoping on optical properties of ZnO:Ag nanograins. Optik (Stuttg). 2020;220(April).

40. Gusmão LA, Peixoto DA, Marinho JZ, et al. Alkali influence on $\mathrm{ZnO}$ and Ag-doped $\mathrm{ZnO}$ nanostructures formation using the microwave-assisted hydrothermal method for fungicidal inhibition. J Phys Chem Solids. 2021;158:110234. Elsevier Ltd,

41. Udom I, Zhang Y, Ram MK, et al. A simple photolytic reactor employing Ag-doped ZnO nanowires for water purification. Thin Solid Films. 2014;564:258-263. Elsevier B.V.,

42. Kim KH, Jin Z, Abe Y, Kawamura M. Structural and optical properties of Cu-, Ag, and Al-doped zinc oxide nanorods. Superlattices Microstruct. 2014;75:455-460. Elsevier Ltd,

43. Denizalti S, Ali AK, Ela C,, Ekmekci M, Erten-Ela S. Dye-sensitized solar cells using ionic liquids as redox mediator. Chem Phys Lett. 2018;691:373-378.

44. Schematic-of-energy-level-diagram-and-electron-transfer-of-ITO-ZnO-TiO2CdSe_fig6_260307381.

45. Singh A, Mohan D, Ahlawat DS, Richa. Performances of spin coated silver doped ZnO photoanode based dye sensitized solar cell. Process Appl Ceram. 2017;11(3):213-219. University of Novi Sad, Faculty of Technology,

46. Debye P. Scattering of X-rays. Ann Phys. 1915;351(6):809-823.

47. Jeong SH, Park BN, Lee SB, Boo JH. Metal-doped ZnO thin films: Synthesis and characterizations. Surf Coatings Technol. 2007;201(9-11 SPEC. ISS.):5318-5322.

48. Lim SP, Pandikumar A, Lim HN, Ramaraj R, Huang NM. Boosting photovoltaic performance of dye-sensitized solar cells using silver nanoparticle-decorated N,SCo-doped-TiO2 photoanode. Sci Rep. 2015;5(April):1-14. Nature Publishing Group,

49. Ravirajan P, Peiró AM, Nazeeruddin MK, et al. Hybrid polymer/zinc oxide photovoltaic devices with vertically oriented $\mathrm{ZnO}$ nanorods and an amphiphilic molecular interface layer. J Phys Chem B. 2006;110(15):7635-7639.

50. Nosheen E, Shah SM, Hussain H, Murtaza G. Photo-sensitization of ZnS nanoparticles with renowned ruthenium dyes N3, N719 and Z907 for application in solid state dye sensitized solar cells: A comparative study. J Photochem Photobiol B Biol. 2016;162:583-591. Elsevier B.V.,

51. Nazeeruddin MK, Baranoff E, Grätzel M. Dye-sensitized solar cells: A brief overview. Sol Energy. 2011;85(6):1172-1178.

52. Sönmezoğlu S, Eskizeybek V, Toumiat A, Avci A. Fast production of $\mathrm{ZnO}$ nanorods by arc discharge in de-ionized water and applications in dye-sensitized solar cells. J Alloys Compd. 2014;586:593-599. 